\title{
Desain Pabrik Pupuk Urea berbahan baku Batubara Kelas Rendah di Kabupaten Muara Enim Sumatera Selatan
}

\author{
Andika Dwimasputra, Naomi Hurayah Aden, Rizky Tetrisyanda, dan Gede Wibawa \\ Departemen Teknik Kimia, Fakultas Teknologi Industri, Institut Teknologi Sepuluh Nopember (ITS) \\ e-mail: gwibawa@chem-eng.its.ac.id
}

\begin{abstract}
Abstrak-Pupuk Urea adalah pupuk kimia mengandung Nitrogen (N) berkadar tinggi. Unsur Nitrogen merupakan zat hara yang sangat diperlukan tanaman. Bahan baku utama pada proses pembuatan pupuk urea adalah gas alam. Namun ketersediaan gas alam semakin menipis jumlahnya, sehingga perlu dikembangkan teknologi proses yang memungkinkan substitusi bahan baku gas sintesis. Bahan baku yang paling memungkinkan untuk menggantikan gas alam adalah batubara, baik melalui teknologi CBM (Coal Bed Methane) maupun teknologi gasifikasi. Produksi pupuk urea melalui 4 tahapan yaitu pembentukan syngas, pemisahan sulphur dari syngas, pembentukan ammonia, dan pembentukan urea. Perbedaan dari proses yang ada, lebih pada perlakuan awal untuk pembentukan syngas (CO dan $\mathrm{H}_{2}$ ). Hal ini disesuaikan kondisi bahan baku yang digunakan (batubara, gas alam, dan biomassa).Dari hasil analisa ekonomi tersebut terlihat bahwa IRR sebesar 34,84\%, dengan POT pada tahun ketiga menginjak tahun keempat. Selain itu, terlihat bahwa fluktuatif bahan baku tidak memberikan pengaruh yang cukup signifikan terhadap kenaikan atau penurunan nilai IRR pabrik. Sehingga pabrik pupuk urea dari bahan batubara kelas rendah berkapasitas 1.25 Juta ton urea/tahun dan 590000 ton ammonia/tahun ini layak didirikan di Tanjung Enim, Muara Enim, Sumatra Selatan pada tahun 2019.
\end{abstract}

Kata Kunci_Gasifikasi, Batubara Kelas Rendah, Pupuk Urea.

\section{PENDAHULUAN}

I NDUSTRI petrokimia merupakan industri strategis yang menghasilkan bahan baku industri manufaktur. Indonesia memiliki Sumber Daya Alam yang cukup besar sebagai bahan baku industri petrokimia. Namun, di Indonesia, industri petrokimia turunan gas alam masih sangat terbatas. Di sektor hulu, industri yang sudah ada adalah industri ammonia dan methanol. Turunan ammonia hanya urea beserta produksi lanjutannya, sedangkan turunan methanol adalah industri formaldehyde, potensi produk turunan lainnya adalah acrylonitrile, caprolactam, methionine, dan sebagainya.

Pupuk Urea digunakan untuk sektor perkebunan dan sektor pertanian di seluruh dunia. Hampir $70 \%$ penggunaan pupuk urea di dunia terpusat di negara China (28\%), India (16\%), USA (12\%), EU (10\%) dan Brazil (6\%). Permintaaan pupuk urea di dunia pada tahun 2016 meningkat 3\% menjadi 111 Megaton, dan diprediksi pada tahun 2020/2021 permintan pupuk urea di dunia mencapai 200 Megaton. Kebutuhan pupuk urea di Indonesia mencapai 11.923 juta ton di tahun 2011 [1]. Semua pabrik pupuk urea di Indonesia menggunakan gas alam sebagai bahan baku, padahal Ketersediaan gas alam yang semakin menipis jumlahnya, sehingga perlu dikembangkan teknologi proses yang memungkinkan substitusi bahan baku gas alam. Bahan baku yang paling memungkinkan untuk menggantikan gas alam adalah batubara. Cadangan batubara Indonesia didominasi oleh batubara dengan kualitas medium dan kualitas rendah. Sumber daya batubara kelas rendah (low rank coal) di Indonesia mencapai 30,57 milyar ton dan perlu dioptimalkan menjadi produk yang bernilai jual lebih. Oleh karena itu, pendirian pabrik pupuk urea dari batubara kualitas rendah sangat potensial dan penting untuk terus dikembangkan.

Lokasi pabrik pupuk urea dari Batubara Kelas Rendah direncanakan akan didirikan di Tanjung Enim, Kabupaten Muara Enim, Sumatera Selatan. Ketersediaan batu bara kelas rendah di provinsi Sumatera Selatan memiliki potensi salah satu yang terbesar di Indonesia yaitu sebesar 51.90 Milyar Ton [2]. Pabrik didirikan dekat dengan sumber bahan baku untuk tetap menjamin kontinuitas pasokan bahan baku dan menekan biaya transportasi. PT. Bukit Asam dipilih sebagai pemasok bahan baku, karena kualitas bahan baku yang sesuai dan daerah operasinya berada di provinsi Sumatera Selatan dengan spesifikasi sebagai berikut [3].

Tabel 1.

Spesifikasi Batubara PT. Bukit Asam Tipe 45

\begin{tabular}{cc}
\hline Parameter & Nilai \\
\hline \hline Total Moisture $(\%$, ar $)$ & 30 \\
Ash Content $(\%$, ar) & 6 \\
Volatile Matter $(\%$, ar $)$ & 35 \\
Fixed Carbon $(\%$, ar) & 29 \\
Calorific Value $(k k a l / k g$, ar) & 4500 \\
Total Sulfur $(\%$, adb) & Max. 1 \\
Ash Fusion Temperature (deformation) $\left({ }^{\circ} \mathrm{C}\right)$ & 1216 \\
Hardgrove Grindable Index & 52 \\
Reactivity & High \\
Caking Characteristic & Non-caking \\
\hline \hline
\end{tabular}

Pabrik dirancang dengan kapasitas produksi pupuk urea sebanyak 1.25 juta ton/tahun dan produksi ammonia sebanyak 590000 ton/tahun. 


\section{URAIAN PROSES}

Proses produksi pupuk urea dengan bahan baku batubara kelas rendah terdiri dari beberapa unit sebagai berikut.

\section{A. Coal Preparation Unit}

Sebelum memasuki proses gasifikasi, batubara kelas rendah harus dipersiapkan terlebih dahulu agar kondisinya sesuai dengan kebutuhan Gasifier yaitu dengan menggunakan hammer mill untuk mengubah ukuran batubara menjadi 1-6 mm. Kemudian low rank coal yang telah dihaluskan dimasukkan ke dalam Screener untuk memisahkan bahan baku yang tidak sesuai ukuran untuk kemudian diproses kembali dalam Hammer Mill. Sedangkan batubara yang telah sesuai ukurannya dialirkan menuju Screw Conveyor Dryer untuk dikeringkan dengan memanfaatkan arus syngas hasil gasifikasi. Batubara kemudian masuk ke Lock Hopper untuk diubah menjadi pulverized coal dari tekanan atmosfer (1 bar) menjadi 30 bar, sesuai dengan kondisi operasi di Gasifier.

\section{B. Coal Gasification Unit}

Setelah tahap persiapan, serbuk batubara diumpankan ke dalam Gasifier. Gasifier yang digunakan berjenis fluidized bed gasifier dengan tipikal proses U-Gas yang bekerja pada kondisi temperatur $900^{\circ} \mathrm{C}$ dan tekanan 30 bar [4]. Gasifier tipe ini memiliki sistem fluidisasi yang membuat heat transfer dan mass transfer antara gas dan partikel batubara solid lebih sempurna. Penggunaan temperatur yang tidak terlalu tinggi juga membuatnya lebih mudah dikontrol dan dikendalikan. Oksidan yang digunakan berupa $\mathrm{O} 2$ dengan tekanan 30 bar. Reaksi yang terjadi pada gasifier adalah [4]:

\section{1) Zona Devolatilisasi}

Batubara $\longrightarrow \mathrm{C}+\mathrm{H}_{2}+\mathrm{O}_{2}+\mathrm{S}+\mathrm{N}_{2}+\mathrm{H}_{2} \mathrm{O}+$ Ash

2) Zona Pembakaran

$\mathrm{C}+\mathrm{O}_{2} \longrightarrow \mathrm{CO}_{2}$

$2 \mathrm{C}+\mathrm{O}_{2} \longrightarrow 2 \mathrm{CO}$

$2 \mathrm{H}_{2}+\mathrm{O}_{2} \longrightarrow 2 \mathrm{H}_{2} \mathrm{O}$

3) Zona Gasifikasi

a. Reaksi Boudourd

$\mathrm{C}+\mathrm{CO}_{2} \longrightarrow 2 \mathrm{CO}$

b. Steam Gasification

$\mathrm{C}+\mathrm{H}_{2} \mathrm{O} \longrightarrow \mathrm{CO}+\mathrm{H}_{2}$

c. Water Gas Shift

$\mathrm{CO}+\mathrm{H}_{2} \mathrm{O} \longrightarrow \mathrm{CO}_{2}+\mathrm{H}_{2}$

4) Reaksi Samping

a. Sulphur Combustion

$\mathrm{S}+\mathrm{O}_{2} \longrightarrow \mathrm{SO}_{2}$

b. $\mathrm{H}_{2} \mathrm{~S}$ Formation

$\mathrm{SO}_{2}+3 \mathrm{H}_{2} \longrightarrow \mathrm{H}_{2} \mathrm{~S}+2 \mathrm{H}_{2} \mathrm{O}$

c. COS Formation

$\mathrm{CO}+\mathrm{S} \longrightarrow \mathrm{COS}$

d. $\mathrm{NO}_{2}$ Formation

$\mathrm{N}_{2}+2 \mathrm{O}_{2} \longrightarrow 2 \mathrm{NO}_{2}$

e. COS Hidrolisis

$$
\mathrm{COS}+\mathrm{H}_{2} \mathrm{O} \longrightarrow \mathrm{H}_{2} \mathrm{~S}+\mathrm{CO}_{2}
$$

Batubara yang terbawa dalam syngas dipisahkan menggunakan Cyclone dan dikembalikan ke dalam Gasifier.
Karbon (char) yang tidak bereaksi pada zona gasifikasi dan semua ash turun sebagai slag di bagian bottom sedangkan syngas yang keluar dari Gasifier akan dialirkan ke dalam Screw Conveyor Dryer untuk menurunkan suhu syngas dari $1000^{\circ} \mathrm{C}$ menjadi $350^{\circ} \mathrm{C}$ sekaligus mengeringkan feed batubara sebelum masuk Gasifier. Syngas kemudian menuju COS Hydrolyzer untuk mengkonversi $\mathrm{COS}$ menjadi $\mathrm{H}_{2} \mathrm{~S}$, dan Syngas akan menuju Desulphurizer tank.

Syngas yang telah tidak ada kandungan COS, kemudian dialirkan ke dalam Desulfurizer Tank untuk menyerap kandungan impurities berupa $\mathrm{H}_{2} \mathrm{~S}$ pada syngas. Hal ini dilakukan karena $\mathrm{H}_{2} \mathrm{~S}$ sangat korosif dan dapat merusak katalis pada reaktor. Adsorban yang digunakan adalah adsorban $\mathrm{ZnO}$ dengan reaksi sebagai berikut:

$$
\mathrm{H} 2 \mathrm{~S}+\mathrm{ZnO} \longrightarrow \mathrm{H} 2 \mathrm{O}+\mathrm{ZnS}
$$

Syngas yang telah bersih dari pengotor $\mathrm{H}_{2} \mathrm{~S}$ kemudian diumpankan menuju water gas shift unit.

\section{Water Gas Shift Unit}

Reaksi shift dilaksanakan dalam 2 tahap yaitu pada suhu tinggi dan suhu rendah. Reaksi tersebut merupakan reaksi eksotermis reversible. Reaksi shift ini membutuhkan temperatur tinggi agar laju reaksi tinggi dan cepat untuk mencapai kesetimbangan tetapi membutuhkan temperatur rendah agar menghasilkan konversi yang maksimal. Oleh karena itu reaksi shift terbagi menjadi dua bagian yaitu pada suhu tinggi dan suhu rendah. High Temperature Shift Reactor berfungsi untuk mengubah $\mathrm{CO}$ menjadi $\mathrm{CO}_{2}$ dengan bantuan katalis $\mathrm{Fe}_{2} \mathrm{O}_{3}$ pada suhu $560.8{ }^{\circ} \mathrm{C}$. Keluaran HTS Reactor kemudian didinginkan dengan menggunakan heat exchanger sebelum memasuki Low Temperature Shift Reactor. LTS Reactor berfungsi untuk mengubah $\mathrm{CO}$ menjadi $\mathrm{CO}_{2}$ yang belum terkonversi di HTS Reactor dengan bantuan katalis tembaga Chromium alumina. Aliran keluar LTS Reactor ini akan menuju $\mathrm{CO}_{2}$ Removal Unit, untuk proses penghilangan $\mathrm{CO}_{2}[5]$.

\section{D. $\mathrm{CO}_{2}$ Removal Unit}

Syngas akan dihilangkan kandungan $\mathrm{CO}_{2}$ dengan cara absorbsi menggunakan solvent MDEA pada $\mathrm{CO}_{2}$ Absorber. Sebelum memasuki absorber syngas ditekan sampai tekanan 56 bar pada Syngas Compressor, dan kemudian didinginkan sampai suhu $32^{\circ} \mathrm{C}$ pada Syngas Cooler, dan akan terbentuk campuran vapor-liquid yang akan dipisahkan menggunakan High Pressure Separator. Vapor dari separator akan menuju ke Absorber, sedangkan bagian liquidnya akan berupa waste water, yang akan di treatment lebih lanjut.

Poduk atas pada $\mathrm{CO}_{2}$ Absorber ini akan menuju $\mathrm{H}_{2}$ Purification Unit. Produk bawah yang banyak kandungan $\mathrm{CO}_{2}$ nya akan menuju $\mathrm{CO}_{2}$ Stripper untuk dipisahkan dengan solvent MDEA, solvent yang telah dipisahkan dengan $\mathrm{CO}_{2}$ akan direcycle kembali ke absorber, dengan tambahan make up MDEA untuk mengganti MDEA yang hilang. Produk atas $\mathrm{CO}_{2}$ Stripper yang mempunyai kandungan $\mathrm{CO}_{2}$ tinggi akan menuju Urea Unit untuk digunakan sebagai bahan baku Urea. 


\section{E. $\mathrm{H}_{2}$ Purification Unit}

Produk atas dari $\mathrm{CO} 2$ Absorber akan menuju Pressure Swing Adsorption untuk dimurnikan kandungan hidrogennya sehingga nantinya akan didapatkan hydrogen dengan kemurnian 99.99\%. Pressure Swing Adsorption ini menggunakan adsorben Zeolite 5A dari UOP [5].

\section{F. Ammonia Synthesis Unit}

Sintesa Ammonia dilakukan terlebih dahulu dengan mencampur gas keluaran dari PSA yang mengandung $\mathrm{H}_{2}$ dengan gas $\mathrm{N}_{2}$ dari unit pemisahan udara dengan perbandingan 3:1 pada Ammonia Reactor. Sebelum masuk ke area sintesa Ammonia, $\mathrm{N}_{2}$ dan $\mathrm{H}_{2}$ melalui kompresor multistage agar tekanan nya mencapai 186,3 bar. Tujuan dari menaikkan tekanan ini yaitu agar konversi pembentukan Ammonia dapat maksimal. Selanjutnya masuk ke heat exchanger untuk dipanaskan hingga mencapai $300^{\circ} \mathrm{C}$. Setelah itu masuk ke reaktor Ammonia dengan reaksi :

$$
\mathrm{N}_{2}+3 \mathrm{H}_{2} \longleftrightarrow 2 \mathrm{NH}_{3}
$$

Ammonia Reactor terdiri dari 4 bed dengan katalis Promoted Iron berupa Ruthenium Base menggunakan teknologi kellog.

\section{G. Ammonia Purification Unit}

Pemurnian bertujuan untuk memurnikan Ammonia yang terbentuk dan untuk mendinginkan gas keluaran reaktor Ammonia agar gas hasil reaksi dapat dipisahkan dengan gas yang belum bereaksi, sehingga kadar Ammonia produk dapat lebih maksimal. Pada proses pemurnian ini terdapat refrigerant system yang memakai pendingin propane untuk menghasilkan Ammonia bersuhu $-33.33{ }^{\circ} \mathrm{C}$. Kemurnian Ammonia liquid keluaran Ammonia Purification Unit ini sebesar 99.9 \% mol. Kemudian Ammonia ini disimpan dalam Ammonia storage.

\section{H. Urea Synthesis Unit}

Proses produksi urea dengan Aces 21 (Advanced Process for Cost and Energy Saving). Dibagi menjadi 3 bagian. Sintesa, Dekomposisi, dan Prilling.

\section{1) Sintesa}

Peralatan utama yang digunakan pada Aces 21 antara lain. Reaktor, stripper, dan carbamate condenser. Urea fasa liquid diumpankan kedalam reactor melalui HP carbamate ejector, yang memberikan driving force untuk sirkulasi pada bagian synthesis loop. Reaktor beroperasi pada N/C rasio 3,7. Suhu $182{ }^{\circ} \mathrm{C}$ dan tekanan $163 \mathrm{~kg} / \mathrm{cm}^{2}$. Reaksi yang terjadi di dalam reactor adalah reaksi pembentukan karbamat dari $\mathrm{NH}_{3}$ dan $\mathrm{CO}_{2}$, serta reaksi dehidrasi karbamat menjadi urea, sebagai berikut.

$$
\begin{gathered}
\mathrm{CO}_{2}+2 \mathrm{NH}_{3} \longleftrightarrow \mathrm{NH}_{2} \mathrm{COONH}_{4} \\
\mathrm{NH}_{2} \mathrm{COONH}_{4} \longleftrightarrow \mathrm{NH} 2 \mathrm{CONH} 2+\mathrm{H} 2 \mathrm{O}
\end{gathered}
$$

Larutan dari reactor ini diumpankan kedalam stripper. Karbamat yang tidak terkonversi mengalami dekomposisi secara termal, dan kelebihan $\mathrm{NH}_{3}$ dan $\mathrm{CO}_{2}$ dipisahkan secara effisien dengan cara stripping dengan gas $\mathrm{CO}_{2}$. Reaksi yang terjadi saat proses stripping adalah

$$
\mathrm{NH}_{2} \mathrm{COONH}_{4} \longleftrightarrow \mathrm{CO}_{2}+2 \mathrm{NH}_{3}
$$

Untuk memenuhi kebutuhan energy dari reaksi dekomposisi karbamat tersebut, maka disuplai steam kedalam stripper. Reaksi dekomposisi karbamat tersebut terjadi pada bagian stripper. Vapor dari stripper dialirkan menuju Carbamate Condenser, sedangkan liquid dari stripper dialirkan menuju MP Decomposer. Gas hasil stripping dari stripper diumpankan kedalam Vertical Submerged Carbamate Condenser (VSCC) yang beroperasi pada N/C rasio 3 suhu $180{ }^{\circ} \mathrm{C}$, dan tekanan $155 \mathrm{~kg} / \mathrm{cm}^{2}$. Amonia dan gas $\mathrm{CO}_{2}$ terkondensasi dan membentuk ammonium karbamat dimana ammonium karbamat yang terbentuk tersebut mengalami dehidrasi untuk membentuk urea pada bagian shell. Reaksi yang terjadi pada Carbamate Condensor adalah

$$
\mathrm{NH}_{2} \mathrm{COONH}_{4} \longleftrightarrow \mathrm{NH}_{2} \mathrm{CONH}_{2}+\mathrm{H}_{2} \mathrm{O}
$$

Vapor yang keluar dari Carbamate Condensor dialirkan menuju bagian Absorbsi bersama dengan vapor dari bagian dekomposisi yang lain yang akhirnya direcycle kembali menuju Carbamate Condensor, sedangkan liquidnya dialirkan menuju reactor sebagai recycle.

2) Dekomposisi

Pada bagian dekomposisi peralatan utama yang digunakan adalah MP Decomposer, LP Decomposer, Urea Solution Heater, Urea Evaporator. Dalam bagian dekomposisi carbamate yang tidak bereaksi didekomposisi menjadi $\mathrm{NH}_{3}$ dan $\mathrm{CO}_{2}$. Unit MP Decomposer dioperasikan pada tekanan $17.5 \mathrm{~kg} / \mathrm{cm}^{2}$ sedangkan LP Decomposer diperasikan pada tekanan $2.5 \mathrm{~kg} / \mathrm{cm}^{2}$. Reaksi yang terjadi pada bagian MP Decomposer dan LP Decomposer adalah

$$
\mathrm{NH}_{2} \mathrm{COONH}_{4} \longleftrightarrow \mathrm{CO} 2+2 \mathrm{NH}_{3}
$$

fraksi liquid keluaran dari LP Decomposer dialirkan menuju Urea Solution Heater. Larutan urea yang keluar dari LP Decomposer selanjutnya akan melalui proses evaporasi untuk meningkatkan konsentrasi urea. Pada proses evaporasi pada unit Urea Evaporator (V-630) dihasilkan larutan urea dengan konsentrasi $97 \%$ dan dialirkan menuju priling tower untuk mengalami proses prilling untuk menghasilkan urea prill.

3) Prilling

Pada bagian ini larutan urea yang konsentrasinya sekitar 97\% di masukan kedalam Distributor untuk selanjutnya dibentuk menjadi urea prill dengan menyemburkan udara secara berlawanan dari bagian bawah prilling tower sehingga terjadi proses pendinginan dan larutan urea menajdi padatan berbentuk prill dengan diameter 1-3,35 $\mathrm{mm}$. Udara dari untuk proses prilling disuplai dari udara sekitar dengan Blower Fludizing Cooler, yang kemudian dipanaskan pada Air Heater sampai suhu $37{ }^{\circ} \mathrm{C}$. Udara tersebut dimanfaatkan untuk mendinginkan larutan urea pekat dari $140{ }^{\circ} \mathrm{C}$ menjadi sekitar $42^{\circ} \mathrm{C}$. 


\section{MATERIAL BALANCE}

Hasil perhitungan material balance menunjukkan bahwa kapasitas produksi Pupuk Urea sebesar 1.25 juta ton/tahun dan produksi ammonia sebesar 590000 ton/tahun membutuhkan bahan baku batubara kelas rendah sebesar 4.3 juta ton/tahun [6][7][8][9].

\section{ANALISA EKONOMI}

Analisa ekonomi dimaksudkan untuk dapat mengetahui apakah suatu pabrik yang direncanakan layak didirikan atau tidak. Untuk itu dilakukan evaluasi atau studi kelayakan dan penilaian investasi. Faktor-faktor yang perlu ditinjau untuk memutuskan hal ini adalah laju pengembalian modal (Internal Rate of Return / IRR), net present value (NPV) waktu pengembalian modal minimum (Pay Out Time / POT), titik impas (Break Even Point / BEP) dan Sensitivitas. Dari hasil perhitungan analisa ekonomi diperoleh Total Cost Investment (TCI) sebesar 313,63 MUSD dengan bunga pinjaman 12\% per tahun dan inflasi $6 \%$ per tahun. Selain itu diperoleh IRR sebesar 34,84\%, POT selama 3,34 tahun, dan BEP sebesar $36,52 \%$. Berdasarkan analisa kepekaan terhadap 4 paramater sensitifitas yaitu fluktuasi biaya investasi, harga bahan baku, harga jual dari produk dan kapasitas produksi, terdapat 4 variabel yang sangat peka terhadap fluktuasi yaitu yaitu harga bahan batubara, harga bahan oksigen, harga produk pupuk urea, dan kapasitas produksi pupuk urea. Umur dari pabrik ini diperkirakan selama 10 tahun dengan masa pembangunannya selama 2 tahun di mana operasi pabrik ini 330 hari/tahun [10][11].

\section{KESIMPULAN/RINGKASAN}

Dari hasil analisa ekonomi didapatkan nilai IRR sebesar $34,84 \%$ yang lebih tinggi dari suku bunga bank per tahun sebesar $12 \%$ dengan pengembalian modal selama 3.34 tahun, Selain itu, terlihat pula bahwa fluktuasi bahan baku tidak memberikan pengaruh yang cukup signifikan terhadap kenaikan atau penurunan nilai IRR pabrik. Sehingga pabrik pupuk urea dari bahan batubara kelas rendah berkapasitas 1,25 Juta ton urea/tahun dan 590.000 ton ammonia/tahun ini layak didirikan di Tanjung Enim, Sumatra Sealatan pada tahun 2019.

\section{DAFTAR PUSTAKA}

[1] I. K. E. dan S. D. M. P. D. dan Informasi, Handbook of Energy \& Economic Statistics of Indonesia. Jakarta: Pusat Data dan Informasi Kementrian ESDM, 2014.

[2] A. Soemanto, "Indonesia Pathway 2050 Calculator: Penyediaan Minyak dan Gas Bumi," J. Miner. Energi, 2014.

[3] Adimnistrator, "Adaro Envirocoal Coal Specifications," 2016. [Online]. Available: http://www.ptba.co.id.

[4] M. Higman, Christopher and Van Der Burgt, Gasification 2nd Ed. Boston: Gulf Profesional Publishing, 2008.

[5] S. Ahn, "Layered Two- and Four-Bed PSA Processes for H2 Recovery from Coal Gas," Elseiver, 2011.

[6] J. B. Himmelblau, David M. Riggs, Basic Principles and Calculations in Chemical Engineering. New Jersey: Prentice Hall International Series in the Physical and Chemical Engineering Sciences, 2004.

[7] S. Van Ness, Introduction to Chemical Engineering Thermodynamics, 4th editio. Singapore: McGraw Hill Inc, 1967.

[8] D. W. Perry, R. H. Green, Perry's Chemical Engineers' Handbook, 6th Ed. New York: Mc Graw-Hill, 1984.

[9] D. Q. Kern, Process Heat Transfer, Internatio. Tokyo: McGrawHill Book Company, 1965.

[10] R. E. W. M.S. Peters, K.D. Timmerhaus, Plant Design and Economics for Chemical Engineers. Boston: Mc Graw Hill, 2003.

[11] G. D. Ulrich, A Guide to Chemical Engineering Process Design and Economic. Canada: John Wiley \& Sons, 1984. 